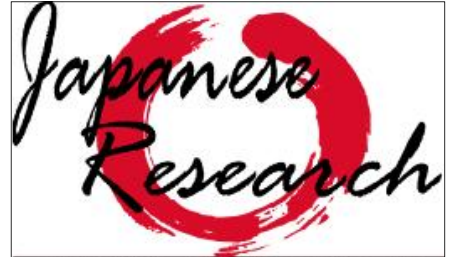

on Linguistics, Literature and Culture
Japanese Research on Linguistics, Literature, and Culture

Vol. 1 No. 2 May 2019, Hal. 129-143

ISSN online: $2655-4836$

http://publikasi.dinus.ac.id/index.php/irllc/article/view/2502/1598

DOI : 10.33633/ir.v1i2.2502

Published by Universitas Dian Nuswantoro, Semarang

\title{
Pengembangan Alat Analisis Humor dalam Komik Jepang
}

\author{
Akhmad Saifudin, Yuyu Yohana Risagarniwa, Elvi Citraresmana, Inu Isnaeni Sidiq \\ Universitas Padjadjaran \\ akhmad17005@mail.unpad.ac.id
}

Article History: Submitted date 2019-04-26; Accepted date 2019-05-25; Published date 2019-06-01

\begin{abstract}
The main objective of this study is to develop a theoretical tool to analyze humor elements in Japanese comic (manga). The authors narrow the definition of "tool" as a theoretical framework that can be used in an inductive research. Developing this tool is of importance since evaluating the quality of humor in comic is difficult and subjective, due to the inclusion of humor as a cognitive and cultural product (Hurley et al, 2011). The authors strongly emphasize that this study was a theoretical review one. We aimed to develop a theoretical foundation pertaining to semiotic analysis in humorous manga products. To achieve the aim, we applied qualitative content analysis to build the foundation inductively. The authors identify that in order to analyze humor in manga, Berger's theory of humor techniques $(1976,1993)$ can be utilized to explore comical effect in manga. Furthermore, Wilson and Sperber's framework (2004) can also be used to evaluate the context of situation pictured in manga. The former theory is imperative since it highlights the function of drawing representation to build humorous atmosphere, while the latter functions to decode the meaning and purpose of humor created by manga creators. To conclude, a theoretical contribution can be withdrawn from the discussion in this study. However, to really measure Japanese's cognitive and cultural values of humor expression, further application of this analysis tool needs to be established in a wider and more comprehensive set of data.
\end{abstract}

Keywords: Comic, Context, Humor, Humor Techniques, Manga

\begin{abstract}
Abstrak
Tujuan utama dari tulisan ini adalah untuk mengembangkan sebuah alat teoretis untuk menganalisis elemen humor dalam komik Jepang (manga). Penulis mempersempit definisi "alat" sebagai kerangka teoretis yang dapat digunakan dalam penelitian induktif. Mengembangkan alat ini sangat penting karena mengevaluasi kualitas humor dalam komik sulit dan subjektif, dikarenakan humor adalah produk kognitif dan budaya (Hurley dkk, 2011). Penulis sangat menekankan bahwa penelitian ini merupakan kajian teoretis. Kami bertujuan untuk mengembangkan landasan teoretis yang berkaitan dengan analisis semiotik dalam produk manga lucu. Untuk mencapai tujuan tersebut, kami menerapkan analisis isi kualitatif untuk membangun pondasi secara induktif. Penulis mengidentifikasi bahwa untuk menganalisis humor
\end{abstract}


dalam manga, teori teknik humor Berger (1976) dapat digunakan untuk mengeksplorasi efek lucu dalam manga. Selanjutnya, kerangka Wilson dan Sperber (2004) juga dapat digunakan untuk mengevaluasi konteks situasi yang digambarkan dalam manga. Teori Berger sangat penting karena menekankan pada fungsi representasi gambar untuk membangun atmosfir yang lucu, sementara Wilson dan Sperber berfungsi untuk memecahkan kode makna dan tujuan humor yang diciptakan oleh pencipta manga. Untuk menyimpulkan, kontribusi teoretis dapat disimpulkan dari pembahasan dalam penelitian ini. Namun, untuk benar-benar mengukur nilai kognitif dan budaya Jepang dari ekspresi humor, penerapan lebih lanjut alat analisis ini perlu dibuat dalam kumpulan data yang lebih luas dan lebih komprehensif.

Kata Kunci: komik, konteks, humor, teknik humor, manga

\section{Pendahuluan}

Dalam tulisan ini humor dianggap sebagai sesuatu, baik verbal maupun nonverbal yang dapat menyebabkan orang tertawa karena situasi yang tidak biasa. Disebut tidak biasa karena pada umumnya humor terjadi karena orang tidak menyangka akan kondisi yang kemudian terjadi. Antara kondisi awal dan kondisi akhir atau selanjutnya, 'dibelokkan' oleh suatu efek kejut 'punch lines' yang menyebabkan orang tertawa karena disadari sebagai sesuatu yang lucu. Dengan demikian dapat dikatakan bahwa humor adalah efek kejut yang menimbulkan kelucuan.

Salah satu media yang banyak memunculkan humor adalah komik. Komik telah dianggap sebagai salah satu media humor yang pada awal sejarahnya digunakan untuk beberapa tujuan, misalnya untuk menghibur tentara saat mereka melawan musuh, untuk menciptakan ketenangan selama perang, dan untuk menyebarkan ideologi politik (Scott, 2011). Tapi, saat ini, tujuan utamanya adalah untuk menghibur orang (pembaca komik). Tujuan eksklusif ini membuat industri komik tumbuh lebih besar. Salah satu industri komik terbesar di dunia adalah manga Jepang. Manga secara konsisten menghasilkan komik terlaris di seluruh dunia. Oleh karena itu, menarik untuk melihat mengapa manga dapat mencapai ketenaran globalnya, meskipun ada pendapat yang menyatakan bahwa manga adalah produk yang terikat budaya sehingga hanya pembaca yang dekat atau mengenal budaya Jepang memahami proposisi tersebut. Salah satu contoh terkenal dalam hal ini adalah manga lucu yang berupa komik strip. 
Meski humor saling terkait dengan kehidupan manusia, humor sulit dipahami karena subjektivitasnya. Subyektivitas terjadi karena humor selalu terhubung dengan pengalaman spesifik yang pada bersumber dari kognisi manusia. Pengalaman bercita rasa khas yang menjadi fosil dan menjadi kebiasaan menciptakan budaya humor. Itulah sebabnya berbagai pengalaman lucu dapat menciptakan budaya humor yang berbeda. Hal inilah yang menjadikan bahwa humor tidak dapat dianggap sebagai sesuatu yang biasa dan dapat digeneralisir, seperti adanya perbedaan yang mencolok antara humor timur versus humor barat (Rauterberg, 2004; Kuiper et al, 2010). Dari argumen ini, penulis berpikir bahwa melakukan penelitian tentang manga lucu diperlukan karena manga lucu mencerminkan budaya dan kognisi Jepang yang secara mengejutkan diakui dan diterima secara global. Fenomena ini menimbulkan dua pertanyaan:

1. Apa yang ada dalam budaya humor Jepang yang dikenal secara global?

2. Bagaimana produk kognitif ini bisa ditransmisikan secara global?

Namun, meneliti humor bukanlah tugas yang mudah. Ruch (2012) menyatakan bahwa "tidak ada definisi atau pengukuran selera humor yang ada sejauh ini". Untuk menambahkan kompleksitasnya, Chandrasekaran dkk (2015) menggarisbawahi bahwa "... mungkin kita belum memiliki pemahaman humor yang terperinci". Penulis percaya bahwa masalahnya ada karena humor adalah masalah kompleks yang membutuhkan pendekatan interdisipliner. Salah satu contoh yang paling lazim adalah penggabungan linguistik kognitif, studi budaya, dan semiotika. Penulis berpendapat bahwa mengintegrasikan analisis dari disiplin yang disebutkan di atas dapat menciptakan kaitan dengan pemahaman manga lucu yang lebih komprehensif. Pertanyaannya mengapa penulis hanya memasukkan ketiga disiplin ini? Pertama, seperti yang kita nyatakan sebelumnya, manga lucu adalah produk pikiran. Pikiran pencipta manga lucu menghasilkan pola bahasa tertentu. Argumen ini didukung oleh Cohn (2012) yang berpendapat "tampaknya ada hubungan intuitif antara komik dan bahasa dalam pikiran penciptanya". Oleh karena itu, fenomena ini hanya bisa diidentifikasi jika penulis memasukkan diskusi yang berkaitan dengan linguistik kognitif dalam penelitian ini. Kedua, manga lucu juga merupakan produk budaya, sehingga diskusi yang berkaitan dengan studi budaya sangat dibutuhkan. Mengapa mereka terkait? Nah, lihat ilustrasi ini. Budaya diwakili dalam berbagai bentuk; salah satunya adalah gerakan 
khusus. Kita sudah tahu bahwa setiap bangsa memiliki isyarat budaya tertentu, seperti isyarat tangan sulingan Italia yang terkenal. Dalam manga lucu, berdasarkan pengamatan penulis, banyak gerakan Jepang dapat digunakan untuk menciptakan efek lucu. Argumen ini sangat didukung oleh Natsume (2001) yang menggarisbawahi pentingnya menggambarkan isyarat dan kebiasaan hidup sehari-hari dalam manga lucu untuk mengungkapkan dan mencerminkan kebiasaan masyarakat Jepang yang sering dialami oleh pencipta manga lucu. Terakhir, hubungan antara komik (atau manga) dan semiotika telah dibahas oleh banyak ilmuwan, seperti Kress dan van Leuween (1996), Magnussen (2000), Engelhardt (2002), D'Angelo dan Cantoni (2006), dan Cohn (2012). Hubungan erat ini terjadi karena studi semiotika membahas "bagaimana representasi, dalam arti luas (bahasa, gambar, dan objek) menghasilkan makna atau proses yang dengannya kita memahami atau mengaitkan makna". Selanjutnya, semiotika telah dikenal sebagai salah satu studi paling awal yang pernah dikaitkan dengan analisis komik atau manga. Hal ini terjadi karena semua bagian manga mewakili sesuatu, dari representasi karakter atau tempat di bagian dalam panel manga (logemes), panel manga (syntactemes), hingga semua urutan (teks) (Koch, 1971; Hünig, 1974) . Argumen kami tentang tiga disiplin di atas akhirnya mengungkapkan bahwa mereka tidak dapat dipisahkan. Bersama-sama mereka bisa membentuk alat teoretis yang bisa digunakan untuk mengevaluasi elemen humor dalam manga, sesuatu yang kurang sekarang (Ruch, 2012; Buijzen dan Valkenburg, 2004).

\section{Kajian Teoretis}

Seperti yang dikemukakan oleh Ruch (2012) dan Chandrasekaran dkk (2015) di bagian sebelumnya, tidak ada parameter baku untuk mengukur atau mengevaluasi humor dalam manga. Secara tradisional, ada empat faktor untuk merasakan humor; Mereka "bisa menertawakan diri sendiri", "kemampuan untuk merasakan humor", "kemampuan untuk menafsirkan humor", dan "kemampuan untuk menciptakan humor" (Ruch, 2012). Penulis berpendapat bahwa ramuan ini tidak cukup dan cukup layak, karena masing-masing dapat ditafsirkan secara berbeda oleh peneliti manga lucu. Oleh karena itu, kami berpikir bahwa perlu dikembangkan alat analisis manga lucu. Tulisan ini akan membahas tentang upaya untuk mengembangkan alat analisis ini dengan menggabungkan tiga disiplin ilmu, yaitu 
semiotika, studi budaya, dan linguistik kognitif. Diskusi tiap-tiap disiplin dijabarkan di bawah ini.

\subsection{Semiotika Humor}

Bukti masa lalu menunjukkan bahwa analisis komik tidak dapat dipisahkan dengan semiotika. Mereka berada dalam ikatan struktural, karena semiotika adalah studi yang meneliti makna tanda dan simbol, dan dua di antaranya menjadi bahan inti dalam komik atau manga (Cohn, 2012). Karena semiotika memiliki diskusi yang luas, dalam menghadapi diskusi teliti tentang semiotika dan manga, para penulis akan menggunakan sub bagian semiotika yang disebut multimodalitas. Menurut Kress dan van Leeuwen di Rivas-Carmona (2014) "teks multimodal adalah yang menggunakan kendaraan komunikasi semiotik yang berbeda-beda (atau" mode "), seperti elemen verbal, paralanguage, kinesik, suara, gambar atau musik, untuk menyampaikan maknanya ". Dengan definisi tersebut, penulis yakin bahwa manga termasuk dalam teks multimodal. Dengan demikian, penelitian ini harus menggarisbawahi terjadinya unsur verbal dan nonverbal dalam manga. Selanjutnya, unsurunsurnya bisa terisolasi atau digabungkan.

Berdasarkan beberapa indikasi, penelitian terdahulu menunjukkan bahwa unsur non verbal terbengkalai. Namun, tradisi ini perlahan memudar, dan studi saat ini menunjukkan bahwa unsur nonverbal sekarang diakomodasi. Sebagian besar studi semiotika-multimodal memusatkan perhatian mereka pada dua pendekatan, yaitu Analisis Wacana Multimoda (selanjutnya disebut MDA) dan Teori Relevansi (RT). Dalam penelitian ini, penulis memfokuskan perhatian mereka pada RT, karena "mencakup semua mode komunikasi dan dapat diterapkan pada pesan verbal dan non-verbal" (Rivas-Carmona, 2014). Dengan memilih pendekatan ini, pembaca manga lucu bisa terikat pada konteks lucu dalam manga dengan menggunakan kepentingan kognitif mereka untuk menafsirkan kejeniusan.

Teori RT dikembangkan oleh Sperber dan Wilson (1986). Mereka mengklaim bahwa makna dibangun tidak hanya dari penguraian pesan linguistik, tetapi juga dari proses yang dialami oleh pembaca manga untuk menguraikan pesan linguistik dan nonlinguistik, baik eksplisit maupun implisit, ditemukan dalam manga. Dari pengertian ini, penulis menyimpulkan bahwa semua pesan yang ditemukan dalam manga menyampaikan pesan "ostensif" atau informasi yang jelas yang bertujuan untuk mengkomunikasikan niat pencipta 
manga. Jadi, dalam penelitian ini, model analisis semiotik dapat diringkas dalam model di bawah ini.

\section{Addresser's Thought/Intention + Context-bound Information $\rightarrow$ Codified $\rightarrow$ Put Across $\rightarrow$ Decodifying + Cognitive Context Information $\rightarrow$ Interpretation (Rivas-Carmona, 2014).}

Dari model tersebut, penulis mengidentifikasi bahwa tujuan dalam memahami pesan dalam manga lucu adalah interpretasi. Namun, interpretasi tidak hanya bergantung pada bahasa yang diartikan, itu juga tergantung pada schemata pembaca atau pengetahuan latar belakang. Yus (di Rivas-Carmona, 2014) mengatakan "tidak semua ujaran ditafsirkan dengan cara yang sama oleh pendengar yang berbeda". Jadi, cukup benar untuk berpikir bahwa dalam sifat kognitif manusia "relevansi adalah relevansi dengan individu" (Sperber and Wilson, 1995). Oleh karena itu, untuk membuatnya layak, "interpretasi" harus dijabarkan. Menurut Wilson dan Sperber (2004), ada tiga subtugas yang digunakan oleh pembaca manga untuk menafsirkan pesan di dalamnya, yaitu sebagai berikut.

1) Membangun hipotesis yang tepat tentang konten eksplisit (explicatures);

2) Membangun hipotesis yang tepat tentang asumsi kontekstual yang dimaksud (premis yang terlibat);

3) Membangun hipotesis yang tepat tentang implikasi kontekstual yang dimaksud (kesimpulan yang disengaja).

Dalam penelitian ini, penulis sengaja menggunakan subtugas ini untuk memanfaatkan makna atau pesan di balik manga humor, dikarenakan ketiganya juga melibatkan kognisi pembaca, kami sangat yakin bahwa ketiganya akan membantu pembaca untuk menyimpulkan anggapan kontekstual manga.

\subsection{Humor dan Budaya}

Humor memang terkait dengan budaya. Ini berarti bahwa humor berhubungan dengan budaya, dan karena itu humor dapat berbeda sesuai dengan pengaruh budayanya yang mereka ikuti. Namun, harus ada universalitas humor umum di antara masyarakat yang berbeda. Dalam penelitian ini, penulis diilhami oleh tipologi humor Berger (1976) yang sejauh ini merupakan teori humor paling universal dan komprehensif sampai saat ini. Menurut Buijzen dan Valkenburg (2004), "tipologi Berger didasarkan pada asumsi bahwa humor dapat dibagi menjadi berbagai bagian atau teknik". Menurut Berger (1976), Tipologi 
humornya terbagi dalam empat yayasan; Mereka adalah bahasa, logika, identitas, dan tindakan. Berikut tipologinya.

Tabel 1. Humor Typology (Bergen in Buijzen and Valkenburg, 2004)

\begin{tabular}{|c|c|}
\hline Humor & Short Description \\
\hline Absurdity & Nonsense, a situation that goes against all logical rules \\
\hline Anthropomorphism & Objects or animals with human features \\
\hline Bombast & Talking in a high-flown, grandiloquent, or rhetorical manner \\
\hline Chase & A pursuit or chase of something or something \\
\hline Clownish Behavior & $\begin{array}{l}\text { Making vigorous arm and leg movements or demonstrating exaggerated } \\
\text { irregular physical behavior }\end{array}$ \\
\hline Clumsiness & Lacking dexterity or grace \\
\hline Coincidence & A coincidental or unexpected occurrence \\
\hline Conceptual Surprise & $\begin{array}{l}\text { Misleading the audience by means of a sudden unexpected change of } \\
\text { concept }\end{array}$ \\
\hline Disappointment & A situation that leads to (minor) disappointment \\
\hline Eccentricity & Someone who deviates from the norms, an odd character \\
\hline Embarrassment & $\begin{array}{l}\text { An awkward situation in which someone gets a sense of discomfort, } \\
\text { uneasiness, or shame }\end{array}$ \\
\hline Exaggeration & $\begin{array}{l}\text { Making an exaggeration or overstatement; reacting in an exaggerated } \\
\text { way; exaggerating the qualities of a person or product }\end{array}$ \\
\hline Grotesque Appearance & $\begin{array}{l}\text { Someone who has a bizarre or monstrous appearance with striking } \\
\text { features }\end{array}$ \\
\hline Ignorance & Someone acts or behaves in a foolish, naïve, gullible, or childish manner \\
\hline Imitation & $\begin{array}{l}\text { Mimicking or copying someone's appearance or movements while keeping } \\
\text { one's own identity at the same time }\end{array}$ \\
\hline Impersonation & Taking on the identity of another person, intentionally or unintentionally \\
\hline Infantilism & Playing with the sound of words \\
\hline Irony & $\begin{array}{l}\text { Saying one thing and meaning something else or exactly (continued) the } \\
\text { opposite of what you're saying }\end{array}$ \\
\hline Irreverent behavior & Lacking proper respect for authority or the prevailing standards \\
\hline Malicious Pleasure & Taking pleasure in other people's misfortune; victim humor \\
\hline Misunderstanding & Misinterpreting a situation \\
\hline Outwitting & $\begin{array}{l}\text { Outsmarting someone or the establishment by retort, response, or } \\
\text { comeback }\end{array}$ \\
\hline Parody & Imitating a style or a genre of literature or other media \\
\hline Peculiar Face & Making a funny face, grimace \\
\hline
\end{tabular}




\begin{tabular}{|c|c|}
\hline Peculiar Music & Funny, unusual music \\
\hline Peculiar Sound & Funny sound, unexpected sound, as in cartoons \\
\hline Peculiar Voice & Funny, unusual voice \\
\hline Pun & Playing with the meaning of words \\
\hline Repartee & Verbal banter, usually in a witty dialogue \\
\hline Repetition & Repetition or replay of the same situation \\
\hline Ridicule & Making a fool of someone, verbally or nonverbally \\
\hline Rigidity & $\begin{array}{l}\text { Someone who thinks along straight lines, who is conservative and } \\
\text { inflexible }\end{array}$ \\
\hline Sarcasm & $\begin{array}{l}\text { Biting remarks made with a hostile tone; sarcasm is always a verbal put- } \\
\text { down }\end{array}$ \\
\hline Satire & $\begin{array}{l}\text { Making a fool or poking fun at well-known things, situations, or public } \\
\text { figures }\end{array}$ \\
\hline Scale & $\begin{array}{l}\text { Very large or small sizes of objects that surpass people's logical } \\
\text { expectations }\end{array}$ \\
\hline Sexual Allusion & Making a reference or insinuation to sexual or naughty matters \\
\hline Slapstick & $\begin{array}{l}\text { Physical pie-in-the-face humor often involving degradation of someone's } \\
\text { status }\end{array}$ \\
\hline Speed & Talking or moving in very fast or slow motion \\
\hline Stereotype & $\begin{array}{l}\text { Stereotyped or generalized way of depicting members of a certain nation, } \\
\text { gender, or other group }\end{array}$ \\
\hline Transformation & $\begin{array}{l}\text { Someone or something takes on another form or undergoes a } \\
\text { metamorphosis; before/after }\end{array}$ \\
\hline Visual Surprise & A sudden unexpected visual/physical change \\
\hline
\end{tabular}

Untuk menciptakan humor, kami sangat percaya bahwa tipologi ini harus saling melengkapi, karena penggunaan tipe humor tunggal tidak menjamin kelucuannya. Dengan melihat lebih dekat tentang penerapan tipologi ini di manga, temuan tersebut dapat digunakan untuk menggambarkan pola humor yang ditemukan dalam manga Jepang.

\subsection{Pengetahuan Kognitif Bahasa Humor}

Karena manga adalah produk gambar dan tulisan, ini berhubungan dengan norma linguistik yang tidak dapat disamakan dengan linguistik "biasa"; bahasa spesifiknya disebut bahasa visual. Mengenai komik dan bahasanya, ilmuwan komik seperti Gubern (1972) mengemukakan pembedaan antara morfem (bentuk representasi) dan warna (warna). Sedangkan Bridgeman (2005) dan Lim (2006) cenderung menghindari diferensiasi dengan mengintegrasikan gambar dan kata-kata. Menurut Cohn (2012), bahasa visual dalam manga dikategorikan menjadi "graphemics, photology (grafis visual analog hingga fonetik dan 
fonologi), morfologi, semantik, tata bahasa ...". Semua kategori di atas tidak benar-benar memiliki definisi "tepat" pada sub-sub bidang linguistik. Dalam graphemics, tidak seperti bentuk fonem suara dalam bahasa lisan, ia menggunakan bentuk dasar mendasar seperti garis atau titik yang dapat digabungkan menjadi gambar lebih besar seperti lingkaran atau persegi untuk menciptakan pemandangan dan objek yang dapat dikenali. Sementara itu, studi fotologi "bagaimana grafem dasar (dalam graphemics) bergabung untuk mempengaruhi makna" (Cohn, 2012). Selanjutnya, dalam morfologi bahasa visual, makna "dapat dibagi serupa dengan pemahaman linguistik standar, dengan morfem produktif atau non-produktif" (Cohn, 2012). Oleh karena itu, seperti dalam bahasa verbal, suppletion, misalnya, juga berfungsi untuk mengganti satu atau semua bagian morfem sebagai alternatif yang lain.

Salah satu contoh yang terkenal adalah mengganti mata karakter dalam manga dengan simbol hati. Semantik mempelajari makna. Beberapa diskusi dalam bahasa lisan atau tulisan semantik juga muncul dalam bahasa visual semantik, misalnya synecdoche (merujuk keseluruhan melalui bagian yang lebih kecil). Cohn (2012) dengan jelas mencontohkan masalah ini dengan jelas dari penjelasannya "Misalnya, kapan saja panel menggunakan" close-up "ekstrem seseorang atau objek, ia menggunakan sekumpulan informasi tentang entitas untuk merujuk keseluruhannya". Akhirnya, tatabahasa yang telah digambarkan sebagai gagasan sentral dalam bahasa juga merupakan isu penting dalam bahasa visual. Dalam bahasa visual, tatabahasa mengacu pada struktur sekuensial fungsi narasi manga, misalnya pola $[[(A)(B) X n[(A B)]]$. Dalam tatabahasa bahasa visual, tanda kurung siku menunjukkan klausa, tanda kurung menunjukkan panel, dengan $A$ dan $B$ menunjukkan karakter yang berbeda dalam manga. Selain itu, $\mathrm{X}$ menunjukkan nama klausa dan $\mathrm{n}$ menunjukkan berapa kali sebelum karakter berkumpul di panel. Ini menjelaskan mengapa sebuah panel dalam manga dapat secara alami dan benar berdampingan dengan panel lain untuk membentuk sebuah cerita yang kohesif. Untuk menyimpulkan, dengan mengidentifikasi bahasa visual di manga, struktur naratif manga yang membangun maknanya bisa ditemukan.

\section{Metodologi Penelitian}


Penulis sangat menekankan bahwa penelitian ini merupakan kajian teoretis. Kami bertujuan untuk mengembangkan landasan teoretis yang berkaitan dengan analisis semiotik dalam produk manga lucu. Untuk mencapai tujuan tersebut, kami menerapkan analisis isi kualitatif untuk membangun pondasi secara induktif. Dalam analisis isi kualitatif, penulis mengumpulkan dan mengambil sampel data dari sebuah buku yang berisi panel manga. Panel manga yang digunakan dalam penelitian ini diambil sampelnya dari Kato et al (2013). Selanjutnya, untuk menganalisis data, penulis meneliti humor di panel manga dengan menerapkan tipologi humor Berger (1976) dan teori relevansi Wilson dan Sperber (2004) dan membuat penjelasan kritis berdasarkan fenomena humor yang ditemukan dalam data.

\section{Pembahasan}

Tujuan utama dari penelitian ini adalah untuk mengembangkan alat analisis semiotik humor dalam manga. Untuk mencapai tujuan tersebut, penulis menyusun daftar teknik humor dan membuat penelitian literatur tentang teori humor dan relevansi. Berikut adalah contoh analisis humor.

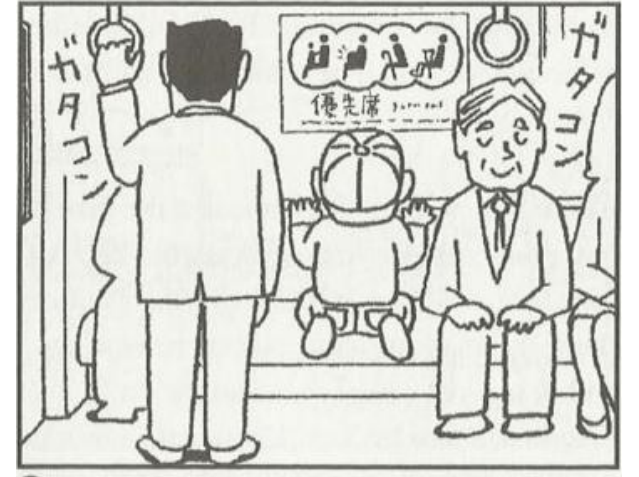

1 (gatakon gatakon) (yuusen-seki)

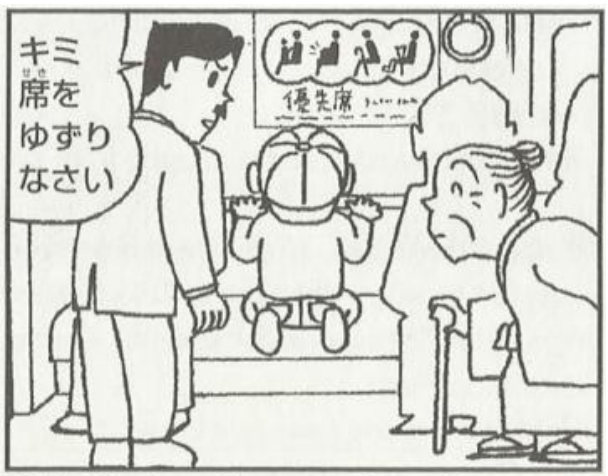

(3) A: Kimi, seki o yuzurinasai.

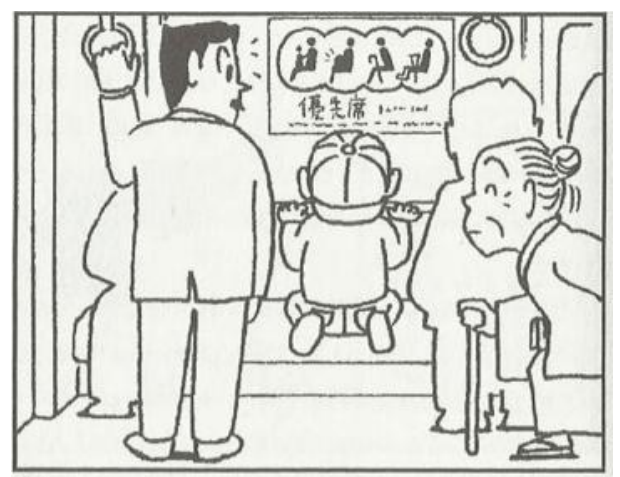

(2)

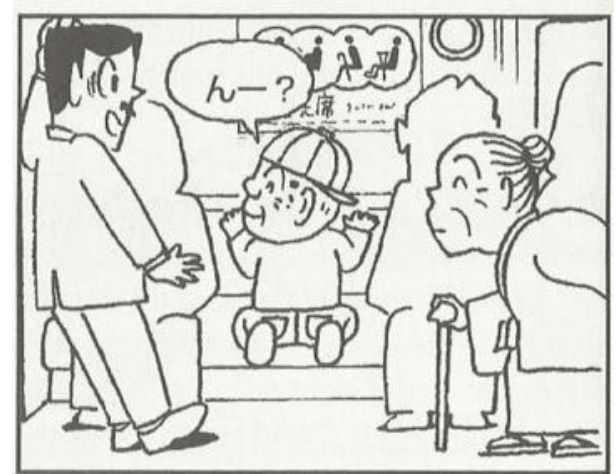

(4) Bnn?

Gambar 1 Data manga 
Berdasarkan panel komik gambar 1, penulis mengidentifikasi bahwa panel memiliki tata bahasa visual tertentu, yaitu $[(A B C)]$ x1 [(ABD)]. Pada empat panel tersebut, mereka menunjukkan terjadinya empat karakter. Tiga adalah karakter utama (ABD) dan satu adalah karakter pendukung (C). Karakter pendukung dapat diidentifikasi saat hanya muncul di salah satu panel dan kemudian hilang di panel berikut, terutama di panel yang menunjukkan klimaks cerita (4). Pertama, penjelasan yang ditunjukkan di panel manga menunjukkan citra tiga orang yang duduk di angkutan umum, kemungkinan besar kereta api. Citra kereta bisa diidentifikasi melalui papan informasi yang biasanya menggambarkan kursi khusus di kereta. Selain itu, panel manga juga secara konsisten menunjukkan pegangan tangan yang menggambarkan alat yang berguna untuk penumpang berdiri di kereta api. Gambar juga menunjukkan empat karakter di manga. Tiga karakter dianggap yang utama, sedangkan satu karakter berperan sebagai karakter pendukung. Karakter utama yang muncul secara konsisten adalah seorang laki-laki yang sedang berdiri $(A)$, orang yang duduk dengan memakai topi (B), dan wanita tua dengan tongkat pendukung (D). Sementara karakter pendukungnya adalah pria duduk yang memakai jas (C). Di panel 1 semua karakter menikmati perjalanan mereka di kereta. Pada panel 2, karakter A memperhatikan masuknya karakter D. Selanjutnya, pada panel 3 karakter A mengatakan sesuatu pada karakter B, kemungkinan besar sebuah peringatan yang berfungsi untuk memperhatikan karakter B tentang masuknya karakter D. Akhirnya di panel 4, karakter C Mengungkapkan wajah dan karakter A nampaknya kaget dengan hal itu. Anehnya, ekspresi wajah karakter D tetap konstan; Ekspresi wajahnya selalu menunjukkan senyuman pada wajah karakter $D$ dari panel 2 sampai 4. Kedua, bangunan implisit yang ditunjukkan di panel manga dapat dilihat dari balon dan caption. Keterangan di panel 1 yang bertuliskan "gatakon-gatakon" menunjukkan bahwa itu adalah suara bunyi kereta berjalan. Sementara balon menunjukkan sepasang percakapan dari karakter A ke karakter B. Balon pertama di panel 3 mengatakan "kimi, seki o yuzurinasai" atau "hei, beri kursi pada wanita tua" (karakter A). Balon kedua di panel 4 mengucapkan "nnn?" Atau "apa yang Anda katakan?" Kesimpulan yang terkait menyiratkan bahwa etika pada transportasi umum, seperti memberi tempat duduk kepada orang tua, entah bagaimana memudar terutama bagi generasi muda Jepang. Premis dapat dibenarkan dari cara karakter A memberi peringatan kuat pada karakter B. Di sini, karakter A berpikir 
bahwa karakter B adalah anak yang dinilai dari penampilan fisik B tubuh dan isyarat tubuh: kecil, memakai topi, kaki di kursi kereta. Namun, ketika karakter B ternyata wajahnya menghadap ke karakter A, ternyata karakter B bukan anak kecil, dia adalah pria yang sangat tua dengan tubuh kecil dan penampilan kekanak-kanakan. Di sisi lain, karakter D menunjukkan wajah yang tenang dan tersenyum menunjukkan bahwa generasi tua Jepang memiliki ketekunan yang tinggi. Dari panel 2 sampai 4, penulis dapat memvalidasi karakter D yang tidak pernah meminta penumpang untuk memberikan tempat duduknya. Dia selalu tersenyum dan terus berdiri di kereta.

Sampai akhir, ada pertanyaan lain yang harus digantung, yaitu "mengapa manga ini lucu?" Untuk menjawab pertanyaan tersebut, kita perlu mempertimbangkan dan menerapkan tipologi humor Berger (1976) ke data manga di atas. Dari keempat panel ini, penulis mengidentifikasi bahwa pencipta manga ini menggabungkan beberapa jenis humor, yaitu: kesalahpahaman, wajah aneh, dan kejutan visual. Penggunaan kesalahpahaman bisa dilihat dari cara karakter salah menafsirkan karakter usia B. Pencipta manga tersebut mengarahkan pikiran pembaca manga untuk menilai secara cepat penampilan fisik dan perilaku seseorang. Tentu saja, pembaca manga tidak berpikir bahwa karakter B sebenarnya adalah orang tua, tapi faktanya menunjukkan sebaliknya. Karena itu, kesalahpahaman ini memicu situasi humoris. Apalagi pencipta manga juga menambahkan wajah aneh untuk memperkuat situasi humoris. Hal itu bisa dilihat di panel 4 yang tidak hanya wajah karakter $B$ yang cukup aneh untuk menimbulkan tawa (efek kejut), tapi juga wajah karakter A yang mengejutkan akan membuat kegembiraan para pembaca. Akhirnya, penulis berpikir bahwa kejutan visual mencakup rangkaian jenis humor di data manga. Kejutan dapat diidentifikasi dari perubahan wajah karakter A dari panel 3 ke panel 4. Seperti yang kita nyatakan di atas, karakter A tidak mengantisipasi situasi, Karena itu ia merasa sangat terkejut karenanya. Dari argumen kami, kami sangat percaya bahwa setiap jenis humor yang ditemukan di data manga tidak selalu menghasilkan humor, semua jenis humor harus digabungkan untuk menciptakan humor. Tapi tidak hanya itu, kita juga dapat menyimpulkan bahwa humor tercipta dari kombinasi bahasa visual yang memicu kognisi pembaca, konteks yang berasal dari semiotik manga, jenis humor yang mengaktifkan tawa pembaca, dan budaya yang akrab bagi pembaca manga. Berdasarkan hasil pembahasan, penulis akhirnya dapat menentukan 
bahwa untuk menganalisis humor dalam manga, kita dapat menggunakan model analitis sebagai berikut.

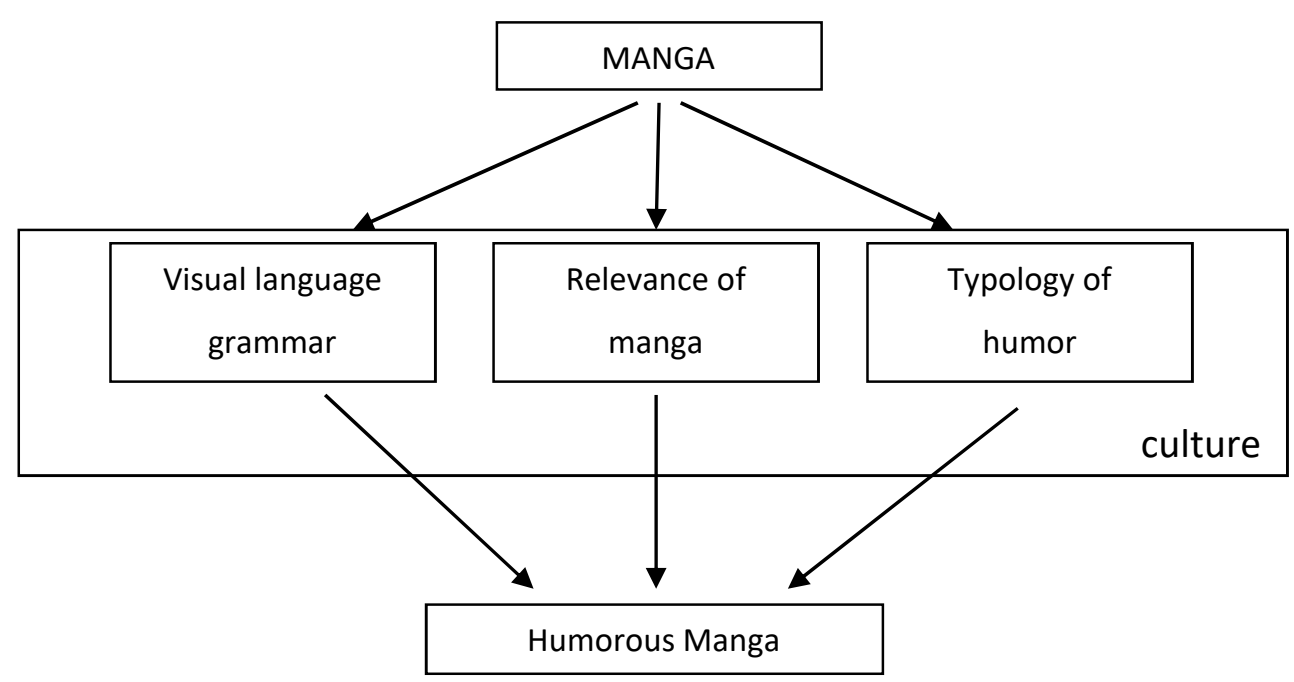

Gambar 2 Model analisis humor manga

\section{Simpulan}

Berdasarkan pembahasan seperti yang telah diuraikan, akhirnya kita dapat menyimpulkan bahwa penulis telah membuat alat analisis untuk meneliti humor dalam manga. Selanjutnya, alat teoretis ini dapat berfungsi sebagai alat fungsional untuk penelitian manga lucu. Kami percaya bahwa manga lucu dapat dianalisis secara kualitatif dari pola bahasa visual, relevansi konteks, dan jenis humor. Ketiga aspek ini saling melengkapi satu sama lain. Namun, kita masih merasa bahwa untuk menilai validitas alat analisis ini, lebih banyak data korpus manga lucu yang perlu diteliti dan mungkin uji kuantitatif juga perlu diperkenalkan untuk menguji reliabilitas alat ini.

\section{Daftar Pustaka}

Berger, A.A. (1976). Laughing matter: A symposium: Anatomy of the joke. Journal of Communication, 26 (3), $113-115$.

Berger, A.A (1993). An Anatomy of Humor. New Brunswick, NJ: Transaction Publishers.

Bridgeman, T. (2005). Figuration and configuration: Mapping imaginary worlds in Bd. In C. Forsdick, L. Grove, and L. Mcquillan (Eds.). The Francophone Bande Desinée. 115-136. Amsterdam: Rodopi. 
Buijzen, M. and Valkenburg, P.M. (2004). Developing a typology of humor in audiovisual media. Media Psychology, 6, 147-167.

Chandrasekaran, A. et al. (2015). We are humor beings: Understanding and predicting visual humor. Retrieved on https://arxiv.org/abs/1512.04407

Cohn, N. (2012). Comics, linguistics, and visual language: The past and future of a field. In F. Bramlett (Ed.). Linguistics and the Study of Comics. New York: Palgrave Macmillan.

D’Angelo, M. and Cantoni, L. (2006). Comics: semiotics approaches. In K. Brown (Ed.). Encyclopedia of Language and Linguistics $2^{\text {nd }} E d$. Vol 2, 627-635. Oxford: Elsevier.

Engelhardt, Y. (2002). The language of graphics. Dissertation. Amsterdam: University of Amsterdam.

Gubern, R. (1972). El lenguaje de los comics. Barcelona: Peninsula.

Hurley, M.M., D.C. Dennett, and R.B. Adams, Jr. (2011). Inside Jokes: Using Humor to Reverse-engineer the Mind. Massachusetts: MIT Press.

Kato, Kiyotataka., et al. (2013). Manga de manabu Nihongo kaiwajutsu. Comics strip by H, Kobayashi. Tokyo: Aruku.

Kress, G. and van Leeuwen, T. (1996). Reading images: The grammar of visual design. London: Routledge.

Kuiper, N.A. et al. (2010). The impact of humor in North American versus Middle East cultures. Europe's Journal of Psychology, 3, 149-173.

Lim, V.F. (2006). The visual semantics stratum: Making meanings in sequential images. In T. Royce and W. Bowcher (Eds.). New Directions in the Analysis of Multimodal Discourse. New Jersey: Lawrence Erlbaum Associates.

Magnussen, A. (2000). The semiotics of C.S. Peirce as a theoretical framework for the understanding of comics. In A. Magnussen and H.-C. Christiansen (Eds.). Comics and Culture: Analytical and Theoretical Approaches to Comics. 193-207. Copenhagen: Museum of Tusculanum Press.

Natsume, F. (2001). East Asia and manga culture: Examining manga-comic culture in East Asia. The Papers of the 2001 Asian Public Intellectuals Fellows. Retrieved on https://arxiv.org/abs/1512.04407

Rauterberg, M. (2004). Enjoyment and entertainment in east and west. International Federation for Information Processing, 176-181.

Rivas-Carmona, M.d.M. (2004). Cartooning for gender equality: A multimodal expression of 'humour' and 'vindication'. Research on Humanities and Social Sciences, 4(24), 8-19.

Ruch, W. (2012). Towards a new structural model of the sense of humor: Preliminary findings. AAAl Technical Report FS-12-02.

Saifudin, A. (2018). Penggunaan Manga Humor dalam Pembelajaran Bahasa dan Penelitian Bahasa Jepang. JAPANEDU: Jurnal Pendidikan dan Pengajaran Bahasa Jepang 2 (2), 99-113.

Scott, C.A. (2011). Comics and conflict: War and patriotically themed comics in American cultural history from world war II through the Iraq war. Dissertations. Chicago: Loyola University Chicago.

Sperber, D. and Wilson, D. (1986). Relevance: communication and cognition. Oxford: Blackwell. 
Sperber, D. and Wilson, D. (1995). Relevance: communication and cognition. $\left(2^{\text {nd }}\right.$ expanded edition). Oxford: Blackwell.

Wilson, D. And D. Sperber. (2004). Relevance theory. In Laurence R. Horn and Gregory Ward (Eds.). Handbook of Pragmatics. London: Blackwell. 